\title{
Application of Two-Stage Network Super-Efficiency DEA to Efficiency Analysis of Chinese Commercial Banks
}

\author{
Qingquan Li, Shiqi Chen ${ }^{D}$, Lu He, Guohui Huang, Rong Li, and Wentsao Pan \\ School of Economics and Management, Hunan University of Science and Engineering, Lingling District, Yongzhou, Hunan, China \\ Correspondence should be addressed to Shiqi Chen; scchen@huse.edu.cn
}

Received 26 October 2021; Revised 3 December 2021; Accepted 9 December 2021; Published 7 February 2022

Academic Editor: Miaochao Chen

Copyright ( 92022 Qingquan Li et al. This is an open access article distributed under the Creative Commons Attribution License, which permits unrestricted use, distribution, and reproduction in any medium, provided the original work is properly cited.

Commercial banks occupy an important leading position in China's banking industry, and their efficiency is of great reference value to the economy of China's financial system, reflecting the current state of China's economy. In this paper, the superefficiency DEA values of 19 commercial banks from 2016 to 2020 are calculated by employing the super-efficiency method into the two-stage network DEA model with constant returns to scale. Compared with the traditional two-stage network DEA model, this method is better. The results show that the calculated values are more accurate than the DEA values measured directly by the twostage network, and the banks with an efficiency value of 1 can be further distinguished. According to the analysis of table data, the operating efficiency of ICBC is the highest, the operating efficiency of the entire banking sector is at a medium level, the second stage has a greater impact on the overall efficiency, and the loan side business needs to be improved.

\section{Introduction}

At present, there are many scholars in various fields at home and abroad to do academic research. The most common research method used by them is the data envelopment analysis (DEA) method. Renowned operations research scientists Charnes et al. [1] first proposed the DEA model (CCR model) under the assumption of the constant returns to scale. Soon, Banker, A. Charnes, and W. W. Cooper (1984) proposed the DEA model (BCC model) under the assumptions of variable returns to scale. The DEA method is a method of evaluating the objects, respectively, by calculating the relative efficiency decision units of the same type. Therefore, the DEA method has been favored by many scholars since it appeared.

In recent years, many scholars have used the original DEA model and even its derivative models to study the efficiency of commercial banks. Zhu et al. [2] examined the performance of 16 major Chinese commercial banks. In particular, we employ a new way of ranking the banks based on their average marginal impact on structural efficiency.
Dimitris et al. [3] presented a general network DEA approach to deal with efficiency assessments in multistage processes. Their approach complies with the composition paradigm, where the efficiencies of the stages are estimated first and the overall efficiency of the system is obtained ex post. Qing et al. [4] measured the relaxation efficiency of the China Commercial Bank from 2008 to 2012 with the twostage DEA method, which regards deposits as an intermediate variable and analyzes the bank's operation process in two stages, and at the same time, considers increasing the ideal output and reducing the bad output to determine the inefficiency. Jamal and Skarleth [5] carried out a DEA analysis of British commercial banks on the basis of the return feedback mechanism of regression. It shows that the British commercial banks do not meet the acceptable level of overall technical efficiency, pure technical efficiency, and scale efficiency at home and abroad. Wang and others [6] introduced the Bootstrap method into the DEA model and calculated efficiency value of the banks with the Bootstrap method before and after the bank is adjusted by the Bootstrap method MATLAB2014. Fan [7] combined DEA 
and super-efficiency DEA methods to analyze the efficiency changes and differences of three types of Chinese banks after the financial crisis and provided opinions on China Banking Reform. Duan and others [8] applied the two-stage DEA model, considered fixed assets, business expenses, and employees as investment indicators and total deposits and total loans as intermediate variables and obtained satisfaction scores, total loans, and total profits as output indicators. They calculated and analyzed the service quality efficiency and profit efficiency of 15 business commercial banks in China between 2008 and 2011 and then analyzed the comprehensive efficiency of each bank. Parisa et al. [9] assessed 13 commercial banks based on a two-stage DEA-R CRA model with asset cost-to-income-to-assets ratio. The method examined the incentive system in detail and then created the incentive system. To sum up, although many scholars use the DEA method to measure and evaluate the efficiency of commercial banks, few people use the two-stage network DEA and super-efficiency together. This paper will comprehensively use the second-stage network DEA with regular payment and the two-stage network DEA with super-efficiency to calculate the DEA values of commercial banks, analyze the results from different aspects, and finally draw the conclusions.

The contribution of this paper is mainly reflected in the use of the efficiency analysis method which is different from the past. This method is more excellent and can improve the accuracy of efficiency value, will be able to obtain new inspiration in the future research, and enhances the efficiency value of the accuracy unceasingly.

The structure of this article is as follows: Section 1 mainly elaborates the domestic and foreign research situation and the related process as well as the article contribution and the structure about the commercial bank efficiency. Section 2 is a detailed introduction of the two-stage network DEA and superefficiency model used in the study of commercial bank efficiency. Section 3 is the concrete analysis and demonstration of the efficiency of commercial banks. Through the analysis of the results of the model, we can evaluate the degree of change of the efficiency of commercial banks and explore the reasons. Section 4 is on the basis of Section 3, through the discussion of the changes in efficiency value, putting forward targeted recommendations and conclusions in the article.

\section{Model Introduction}

2.1. DEA Model. The DEA model is divided into a CCR model whose large-scale remuneration is constant and a BCC model of scale reward. This paper will test commercial bank efficiency based on the former two-stage network DEA. In the two-stage network DEA model, there are $m$ decision units (DMUS) and each decision unit is a $\mathrm{DMU} j, j=1,2, \ldots$, $m$, There are $n$ input elements, that is, $X_{c j}$ in the first phase, where $c=1,2, \ldots, n$, and $p$ output factors, that is, $Z_{i j}, i=1,2$, $\ldots, p$. At the same time, the output in the first stage is also used as the input in the second phase. Supposing there are $q$ output elements, that is, $Y_{d j}$ in the second phase, where $d=1$, $2, \ldots, q$, according to the assumption above, the corresponding two-stage network DEA model is

$$
\begin{aligned}
& \min \theta=E_{k}^{1-\mathrm{CCR}} k=1,2, \ldots, n \\
& \sum_{j=1}^{m} \lambda_{j} X_{c j} \leq \theta X_{c k}, \quad c=1,2, \ldots, n \\
& \text { S.t. } \sum_{j=1}^{m} u_{j} Y_{i j} \leq X_{d k}, \quad d=1,2, \ldots, q \\
& \sum_{j=1}^{m} \lambda_{j} Z_{i j} \leq \sum_{j=1}^{m} u_{j} Z_{i j}, \quad i=1,2, \ldots, p \\
& u_{j}, \lambda_{j} \geq 0, \theta \leq 1 .
\end{aligned}
$$

2.2. Super-Efficiency Two-Stage Network DEA. The superefficiency DEA value is based on the efficiency value calculated by the traditional DEA model, which can be used to determine the effectiveness of the scale technology. If the efficiency value is greater than or equal to 1 , the scale technology is active; if the efficiency value is less than 1 , the scale or the technology is invalid. This method can better compare and sort each decision unit than the DEA model and can further distinguish a decision unit which has efficiency value of 1 in the conventional DEA model. According to the hypothesis conditions in model (1), we will select a decision unit and the expression of its super-efficiency value is as follows.

The first stage is

$$
\begin{array}{ll}
\min \theta & \\
& \sum_{j=1, j \neq j_{0}}^{m} \lambda_{j} X_{c j}+s_{c}^{-}=\theta X_{c j}, \quad r=1,2, \ldots, n \\
\text { s.t. } & \sum_{j=1, j \neq o}^{m} \lambda_{j} Z_{i j}-s_{i}^{+}=Z_{i 0}, \quad i=1,2, \ldots, p \\
& \lambda_{j}, s_{c}^{-}, s_{i}^{+} \geq 0, \quad j=1,2, \ldots, m .
\end{array}
$$

The second stage is

$\min \theta$

$$
\begin{aligned}
& \sum_{j=1, j \neq j_{0}}^{m} \lambda_{j} Z_{i j}+s_{i}^{-}=\theta Z_{i j}, \quad i=1,2, \ldots, p \\
\text { s.t. } & \sum_{j=1, j \neq o}^{m} \lambda_{j} Y_{d j}-s_{d}^{+}=Z_{d 0}, \quad d=1,2, \ldots, q \\
& \lambda_{j}, s_{i}^{-}, s_{d}^{+} \geq 0, \quad j=1,2, \ldots, m .
\end{aligned}
$$

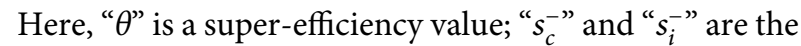
input relaxation variables of the decision unit; and " $s_{i}^{+}$" and " $s_{d}^{+}$" are the output relaxation variables of the decision unit.

\section{Empirical Analysis}

3.1. Indicator Selection. When studying and analyzing efficiency problems of banks, the choice of inputting output indicators is especially critical. Generally, the cost method and the mediate method are used to select properly, and the 
latter is selected as the indicator in the paper. The investment indicators and output indicators are as follows.

The first stage: investment indicators are fixed assets, business expenditures, and management fees, and the output indicator is total loan. (The unit is 100 million yuan.)

The second stage: the investment index is the total loan and employee salary, and output indicator is net profit. (The unit is 100 million yuan.)

The total amount of loans represents the total amount of debt or financing that a business borrows from a bank. This paper uses the total loan as the intermediate variable. They are both outputs in the first stage and inputs in the second stage. This paper sets two stages, both of which find operational efficiency. The first phase puts assets and funds for customer loans as the substrate; the higher the efficiency value, the better the operational effect. And, the second stage not only puts the total amount of output loans in the first stage but also adds the employee salary, and finally the profit is obtained. The same as before, the higher the efficiency value, the better the operational effect. The bank's operation can be assessed by seeing the entire process as having comprehensive efficiency value. The relationship between the input and output indexes of each stage is shown in Figure 1.

3.2. Source of Sample Data. In this paper, 19 commercial banks were selected for research and analysis, which are 5 large-scale state-owned commercial banks such as Industrial and Commercial Bank and Agricultural Bank, five other large state-owned commercial banks, such as Shanghai Pudong Development Bank and CITIC Bank, nine jointstock commercial banks such as Pudong Development Bank and CITIC Bank, and five city commercial banks such as Bank of Jiangsu. The surrogate names of each bank are shown in Table 1. The investment output indicator data come from the annual financial statements of the banks of the Oriental Wealth, and the deadline is from 2016 to 2020.

3.3. Descriptive Analysis. Based on the sample data from 2016 to 2019 , this paper averages each variable and creates a line chart to highlight the five-year trend, as shown in Figure 2. As can be seen from Figure 2, the total amount of loans has been increasing year by year and the growth rate is getting faster and faster. Therefore, we take the total amount of loans as the intermediate variable and study what causes this. By the way, the other five variables were virtually unchanged over five years.

3.4. Analysis of Bank Efficiency Results. Based on the twostage network DEA model, the sample data are calculated by using the MAXDEA and the traditional network DEA, respectively, then we apply super-efficiency on the basis of this, and finally, each efficiency value is obtained. The results are shown in Tables 2-4. As can be seen from Tables 2-4, in the same year, the results of the two-stage network DEA measurement have the same time sequence and multiple efficiency values (1). Among them, there are ICBC Bank and Beijing Bank in 2016, ICBC Bank and Industrial Bank in
2017, and ICBC Bank in 2019 and 2020. In addition, there are also the second-stage ICBC Bank in 2020 and the wholestage's ICBC Bank and Industrial Bank, and ICBC Bank in 2019. Therefore, the super-efficiency is introduced to the second-stage network DEA, and the test results are as follows, showing if the efficiency value of 1 is further distinguished, the result value will be better. The results are calculated based on the superior efficiency of two-stage network DEA.

As can be seen from Table 2, most of the bank stages have the highest efficiency value in 2016, indicating that the more the number of customer loans, the better the operating efficiency. And, the value of the bank's efficiency has a decline in the cost of operation from 2016 to 2020, but not less than 0.75 , indicating that the entire banking industry is in good condition. The efficiency value of the IRBC is in the vicinity of 1 in five years, showing that the operational efficiency is excellent. The CITIC Bank and Minsheng Bank have a lower efficiency, with a value less than 1 , indicating that the scale technology is invalid. Industrial and Commercial Bank has the highest efficiency value every year, indicating its best operating conditions; Ping An Bank has the lowest efficiency value in 2018 and 2019, and as the year goes, the result value is getting lower and lower, indicating that the operating conditions are poor. There is less traffic in loans, and there is a need to improve system and operational strategies as soon as possible. In addition, from the data in the table, the efficiency average is relatively stable, but more than $50 \%$ of bank efficiency is lower than the average, indicating that the entire bank business efficiency is in the medium level, but more than half of the banks' operating efficiency is lower than the average.

Table 3 shows that in addition to the ICBC Bank, the remaining bank efficiency values are mostly below 0.75 , indicating that the operating efficiency and the profit are low. More than half of the bank efficiency values in stage II are lower than their average in each year, indicating that the operating efficiency is not good. It is advised to adjust loan interest rate. In conjunction with Tables 2 and 3, the first stage of the efficiency value is generally higher than the second stage's and most of the bank efficiency values are less than 1, indicating that Chinese banking operation is uneven and the scale technology is invalid.

It is known from Table 4 that the highest efficiency in 2016 was shown by Beijing Bank, followed by the Industrial and Commercial Bank, and the highest efficiency from 2017 to 2020 was shown by the Industrial and Commercial Bank. On the whole, the Industrial and Commercial Bank is ranked first in the banking industry, its operating efficiency is in the leading position, and the Industrial and Commercial Bank's efficiency values are greater than 1 in 2017, 2019, and 2020, indicating that its scale technology is effective. CITIC Bank, Huaxia, and other local banks' efficiency values are relatively low, less than 1, indicating that the operating conditions are poor and the scale technology is invalidated compared with the state-owned banks or joint-stock banks. Ping An Bank, in particular, had the lowest efficiency value for two consecutive years, which was substantially lower than the banking industry as a whole. 


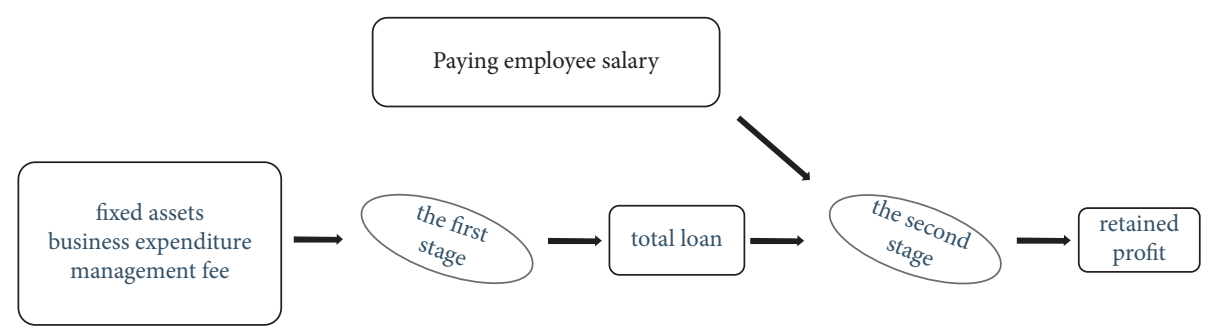

FIgURE 1: Diagram of the relationship between input and output indexes.

TABLE 1: Surrogate names of banks.

\begin{tabular}{lc}
\hline ICBC & A \\
Construction Bank & B \\
ABC & C \\
Bank of China & D \\
Bank of Communications & E \\
CITIC Bank & $\mathrm{F}$ \\
Minsheng Bank & $\mathrm{G}$ \\
China Merchants Bank & $\mathrm{H}$ \\
HSBC Bank & $\mathrm{I}$ \\
Everbright Bank & $\mathrm{J}$ \\
Industrial Bank & $\mathrm{K}$ \\
Shanghai Pudong Development Bank & $\mathrm{L}$ \\
Zheshang Bank & $\mathrm{M}$ \\
Ping An Bank & $\mathrm{N}$ \\
Ningbo Bank & $\mathrm{O}$ \\
Nanjing Bank & $\mathrm{P}$ \\
Hangzhou Bank & $\mathrm{Q}$ \\
Bank of Beijing & $\mathrm{R}$ \\
Jiangsu Bank & $\mathrm{S}$ \\
\hline
\end{tabular}

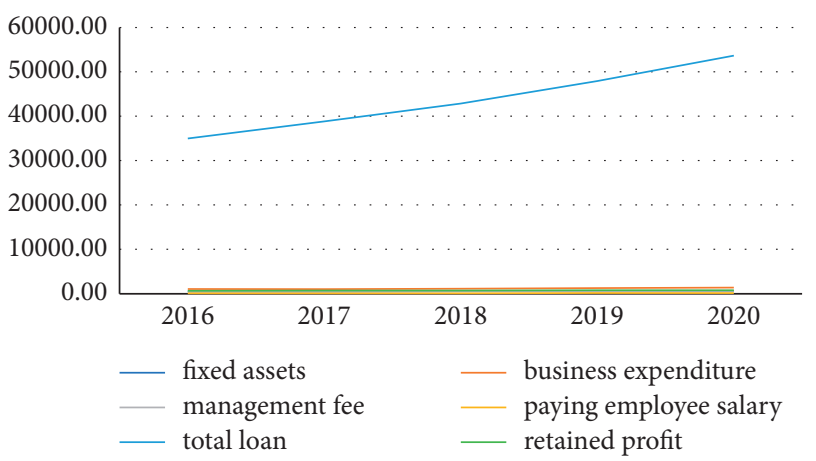

FIgURE 2: Changes in each variable over five years.

In conjunction with Tables 2-4, various types of banks have high efficiency in stage 1 , which indicated that the first stage of operation is good. The second stage efficiency value is low, indicating that the second stage is not good. What is more, the efficiency value of the total stage is subject to stage 1 or stage 2 , and most result values are between two types of stage efficiency values. From the variety of banks, large-scale state-owned banks operate superior to joint-stock banks, and local banking is the lowest.

The average value of the bank's efficiency by stage and the overall average value for 2016-2020 are compiled from Tables 2-4, as shown in Table 5. The efficiency value of ICBC Bank in terms of comprehensive efficiency is greater than 1; thus, the super-efficiency two-stage networks are effective, indicating that their scale technology is effective, and other banks are scale ineffective or technology ineffective. Stage 1 results show that the efficiency value of ICBC Bank is greater than 1, which is better, and the bank with the highest efficiency among 19 banks in stage 1 is ICBC Bank, while the lowest efficiency was shown by Ping An Bank. The efficiency value measured in stage 2 shows that only ICBC Bank has an efficiency value greater than 1 and is the most efficient among 19 banks, while Ping An Bank is still the least efficient. According to the efficiency values of stage 1 and stage 2 , the highest comprehensive efficiency was shown by ICBC with a value of 1.0819 and the lowest value was shown by Ping An Bank with an efficiency value of 0.4007 , indicating that the ICBC Bank had the highest operational efficiency and Ping An Bank had the lowest, reflecting that the DEA value of the super-efficient two-stage network is influenced by the combined effect of stage 1 and stage 2 efficiency.

From the data in Table 5, we can see that the total average efficiency value of stage 1 is about 0.7371 , the total average efficiency value of stage 2 is about 0.5532 , and the total average overall efficiency value is about 0.6452 . From the efficiency value of each bank in the table, half of the banks in stage 1 and stage 2 and their overall efficiency have values below the overall average value of their corresponding stages, which means that half of the banks have efficiency values less than the industry values. This means that half of the banks have values less than the industry average. In addition, the average efficiency value of stage 1 is greater than the average efficiency value of stage 2 , which shows that the efficiency value of stage 2 is lower overall.

From the analysis of individual banks, the last three in the ranking of efficiency values are Ping An Bank with an overall efficiency value of 0.4007 , Huaxia Bank with 0.4553, and CITIC Bank with 0.4990, indicating that the banks with the lowest operational efficiency are Ping An, Huaxia, and CITIC Bank in order. Combining stage 1 and stage 2 to analyze the overall efficiency, ICBC has the highest efficiency value in both stage 1 and stage 2 and both values are higher than the average, thus increasing its overall efficiency; Bank of Communications has a lower average efficiency value in stage 1 and a higher average efficiency value in stage 2, so Bank of Communications is affected by stage 1 , resulting in a lower overall average efficiency value; Ping An Bank has a stage 2 efficiency value of 0.2565 , which is substantially lower than the overall stage 2 efficiency average, resulting in its low comprehensive efficiency value and thus it is known to have lower operating efficiency. 
TABLE 2: Measurement results of various banks in stage 1 .

\begin{tabular}{lcccccccccc}
\hline $\begin{array}{l}\text { Year } \\
\text { DMU }\end{array}$ & 2016 & \multicolumn{2}{c}{$\begin{array}{c}2017 \\
\text { Two-stage network DEA }\end{array}$} & 2018 & 2019 & 2020 & 2016 & 2017 & $\begin{array}{c}2018 \\
\text { Super-efficiency }\end{array}$ two-stage network DEA \\
\hline A & 1.0000 & 1.0000 & 0.9448 & 1.0000 & 1.0000 & 1.0000 & 1.1071 & 0.9448 & 1.1067 & 1.3901 \\
B & 0.9924 & 0.9000 & 0.8435 & 0.7988 & 0.8429 & 0.9924 & 0.9000 & 0.8435 & 0.7988 & 0.8429 \\
C & 0.8135 & 0.7415 & 0.6344 & 0.6708 & 0.7327 & 0.8135 & 0.7415 & 0.6344 & 0.6708 & 0.7327 \\
D & 0.9270 & 0.8086 & 0.7659 & 0.7058 & 0.7173 & 0.9270 & 0.8086 & 0.7659 & 0.7058 & 0.7173 \\
E & 0.8280 & 0.7208 & 0.6505 & 0.6753 & 0.5862 & 0.8280 & 0.7208 & 0.6505 & 0.6753 & 0.5862 \\
F & 0.7292 & 0.6035 & 0.5525 & 0.5184 & 0.5305 & 0.7292 & 0.6035 & 0.5525 & 0.5184 & 0.5305 \\
G & 0.6944 & 0.7000 & 0.5910 & 0.5760 & 0.3395 & 0.6944 & 0.7000 & 0.5910 & 0.5760 & 0.3395 \\
H & 0.7016 & 0.6737 & 0.6288 & 0.7637 & 0.7514 & 0.7016 & 0.6737 & 0.6288 & 0.7637 & 0.7514 \\
I & 0.6821 & 0.6138 & 0.5212 & 0.5004 & 0.4882 & 0.6821 & 0.6138 & 0.5212 & 0.5004 & 0.4882 \\
J & 0.7802 & 0.7700 & 0.5811 & 0.5603 & 0.5777 & 0.7802 & 0.7700 & 0.5811 & 0.5603 & 0.5777 \\
K & 0.9972 & 1.0000 & 0.8970 & 0.8104 & 0.8115 & 0.9972 & 1.0000 & 0.8970 & 0.8104 & 0.8115 \\
L & 0.9501 & 0.7723 & 0.7048 & 0.6773 & 0.6661 & 0.9501 & 0.7723 & 0.7048 & 0.6773 & 0.6661 \\
M & 0.8540 & 0.8069 & 0.6314 & 0.5235 & 0.6161 & 0.8540 & 0.8069 & 0.6314 & 0.5235 & 0.6161 \\
N & 0.7165 & 0.6736 & 0.4822 & 0.4568 & 0.3951 & 0.7165 & 0.6736 & 0.4822 & 0.4568 & 0.3951 \\
O & 0.7919 & 0.7651 & 0.7299 & 0.8421 & 0.8655 & 0.7919 & 0.7651 & 0.7299 & 0.8421 & 0.8655 \\
P & 0.7362 & 0.9176 & 0.8335 & 0.8491 & 0.7518 & 0.7362 & 0.9176 & 0.8335 & 0.8491 & 0.7518 \\
Q & 0.7565 & 0.7935 & 0.7531 & 0.6128 & 0.6719 & 0.7565 & 0.7935 & 0.7531 & 0.6128 & 0.6719 \\
R & 1.0000 & 0.8364 & 0.7784 & 0.7162 & 0.7163 & 1.0000 & 0.8364 & 0.7784 & 0.7162 & 0.7163 \\
S & 0.7667 & 0.7607 & 0.7273 & 0.6902 & 0.5901 & 0.7667 & 0.7607 & 0.7273 & 0.6902 & 0.5901 \\
Average & 0.8272 & 0.7820 & 0.6974 & 0.6815 & 0.6658 & 0.8272 & 0.7876 & 0.6974 & 0.6871 & 0.6864 \\
\hline
\end{tabular}

TABLE 3: Measurement results of various banks in stage 2.

\begin{tabular}{|c|c|c|c|c|c|c|c|c|c|c|}
\hline \multirow{2}{*}{$\begin{array}{l}\text { Year } \\
\text { DMU }\end{array}$} & 2016 & 2017 & 2018 & 2019 & 2020 & 2016 & 2017 & 2018 & 2019 & 2020 \\
\hline & \multicolumn{5}{|c|}{ Two-stage network DEA } & \multicolumn{5}{|c|}{ Super-efficiency two-stage network DEA } \\
\hline A & 0.9646 & 0.9823 & 0.9311 & 0.9380 & 1.0000 & 0.9646 & 0.9823 & 0.9311 & 0.9380 & 1.1067 \\
\hline $\mathrm{B}$ & 0.7310 & 0.8617 & 0.7402 & 0.7919 & 0.7988 & 0.7310 & 0.8617 & 0.7402 & 0.7919 & 0.7988 \\
\hline $\mathrm{C}$ & 0.5432 & 0.6784 & 0.4691 & 0.5517 & 0.6708 & 0.5432 & 0.6784 & 0.4691 & 0.5517 & 0.6708 \\
\hline $\mathrm{D}$ & 0.6274 & 0.7772 & 0.5966 & 0.6812 & 0.7058 & 0.6274 & 0.7772 & 0.5966 & 0.6812 & 0.7058 \\
\hline $\mathrm{E}$ & 0.9223 & 0.8751 & 0.8354 & 0.7430 & 0.6753 & 0.9223 & 0.8751 & 0.8354 & 0.7430 & 0.6753 \\
\hline $\mathrm{F}$ & 0.5048 & 0.6170 & 0.4511 & 0.5018 & 0.5184 & 0.5048 & 0.6170 & 0.4511 & 0.5018 & 0.5184 \\
\hline G & 0.5140 & 0.6042 & 0.4742 & 0.5326 & 0.5760 & 0.5140 & 0.6042 & 0.4742 & 0.5326 & 0.5760 \\
\hline $\mathrm{H}$ & 0.9429 & 0.8222 & 1.0000 & 0.8144 & 0.7637 & 0.9429 & 0.8222 & 1.0000 & 0.8144 & 0.7637 \\
\hline I & 0.2852 & 0.4836 & 0.3796 & 0.4504 & 0.5004 & 0.2852 & 0.4836 & 0.3796 & 0.4504 & 0.5004 \\
\hline $\mathrm{J}$ & 0.4601 & 0.6202 & 0.4405 & 0.5108 & 0.5603 & 0.4601 & 0.6202 & 0.4405 & 0.5108 & 0.5603 \\
\hline $\mathrm{K}$ & 0.4595 & 0.7283 & 0.4187 & 0.6579 & 0.8104 & 0.4595 & 0.7283 & 0.4187 & 0.6579 & 0.8104 \\
\hline $\mathrm{L}$ & 0.8896 & 0.9199 & 0.5649 & 0.6348 & 0.6773 & 0.8896 & 0.9199 & 0.5649 & 0.6348 & 0.6773 \\
\hline M & 0.3752 & 0.6146 & 0.3026 & 0.4670 & 0.5235 & 0.3752 & 0.6146 & 0.3026 & 0.4670 & 0.5235 \\
\hline $\mathrm{N}$ & 0.2864 & 0.5015 & 0.2126 & 0.3474 & 0.4568 & 0.2864 & 0.5015 & 0.2126 & 0.3474 & 0.4568 \\
\hline $\mathrm{O}$ & 0.4944 & 0.6431 & 0.5234 & 0.6267 & 0.8421 & 0.4944 & 0.6431 & 0.5234 & 0.6267 & 0.8421 \\
\hline $\mathrm{P}$ & 0.4206 & 0.5784 & 0.3595 & 0.5965 & 0.8491 & 0.4206 & 0.5784 & 0.3595 & 0.5965 & 0.8491 \\
\hline Q & 0.3103 & 0.5334 & 0.3247 & 0.5389 & 0.6128 & 0.3103 & 0.5334 & 0.3247 & 0.5389 & 0.6128 \\
\hline $\mathrm{R}$ & 1.0000 & 1.0000 & 0.7206 & 0.7495 & 0.7162 & 1.0779 & 1.0389 & 0.7206 & 0.7495 & 0.7162 \\
\hline$S$ & 0.3098 & 0.5382 & 0.2660 & 0.4967 & 0.6902 & 0.3098 & 0.5382 & 0.2660 & 0.4967 & 0.6902 \\
\hline Average & 0.5811 & 0.7042 & 0.5269 & 0.6122 & 0.6815 & 0.5852 & 0.7062 & 0.5269 & 0.6122 & 0.6871 \\
\hline
\end{tabular}


TABLE 4: Measurement results of various banks overall.

\begin{tabular}{|c|c|c|c|c|c|c|c|c|c|c|}
\hline \multirow{2}{*}{$\begin{array}{l}\text { Year } \\
\text { DMU }\end{array}$} & 2016 & 2017 & 2018 & 2019 & 2020 & 2016 & 2017 & 2018 & 2019 & 2020 \\
\hline & \multicolumn{5}{|c|}{ Two-stage network DEA } & \multicolumn{5}{|c|}{ Super-efficiency two-stage network DEA } \\
\hline A & 0.9823 & 1.0000 & 0.9380 & 1.0000 & 1.0000 & 0.9823 & 1.1071 & 0.9380 & 1.1067 & 1.1062 \\
\hline B & 0.8617 & 0.9000 & 0.7919 & 0.7988 & 0.8583 & 0.8617 & 0.9000 & 0.7919 & 0.7988 & 0.8583 \\
\hline $\mathrm{C}$ & 0.6784 & 0.7415 & 0.5517 & 0.6708 & 0.5256 & 0.6784 & 0.7415 & 0.5517 & 0.6708 & 0.5256 \\
\hline $\mathrm{D}$ & 0.7772 & 0.8086 & 0.6812 & 0.7058 & 0.7005 & 0.7772 & 0.8086 & 0.6812 & 0.7058 & 0.7005 \\
\hline E & 0.8751 & 0.7208 & 0.7430 & 0.6753 & 0.7907 & 0.8751 & 0.7208 & 0.7430 & 0.6753 & 0.7907 \\
\hline F & 0.6170 & 0.6035 & 0.5018 & 0.5184 & 0.2918 & 0.6170 & 0.6035 & 0.5018 & 0.5184 & 0.2918 \\
\hline G & 0.6042 & 0.7000 & 0.5326 & 0.5760 & 0.6419 & 0.6042 & 0.7000 & 0.5326 & 0.5760 & 0.6419 \\
\hline $\mathrm{H}$ & 0.8222 & 0.6737 & 0.8144 & 0.7637 & 0.9040 & 0.8222 & 0.6737 & 0.8144 & 0.7637 & 0.9040 \\
\hline I & 0.4836 & 0.6138 & 0.4504 & 0.5004 & 0.4146 & 0.4836 & 0.6138 & 0.4504 & 0.5004 & 0.4146 \\
\hline $\mathrm{J}$ & 0.6202 & 0.7700 & 0.5108 & 0.5603 & 0.3413 & 0.6202 & 0.7700 & 0.5108 & 0.5603 & 0.3413 \\
\hline K & 0.7283 & 1.0000 & 0.6579 & 0.8104 & 0.4685 & 0.7283 & 1.0000 & 0.6579 & 0.8104 & 0.4685 \\
\hline $\mathrm{L}$ & 0.9199 & 0.7723 & 0.6348 & 0.6773 & 0.5871 & 0.9199 & 0.7723 & 0.6348 & 0.6773 & 0.5871 \\
\hline M & 0.6146 & 0.8069 & 0.4670 & 0.5235 & 0.3688 & 0.6146 & 0.8069 & 0.4670 & 0.5235 & 0.3688 \\
\hline $\mathrm{N}$ & 0.5015 & 0.6736 & 0.3474 & 0.4568 & 0.2470 & 0.5015 & 0.6736 & 0.3474 & 0.4568 & 0.2470 \\
\hline $\mathrm{O}$ & 0.6431 & 0.7651 & 0.6267 & 0.8421 & 0.7071 & 0.6431 & 0.7651 & 0.6267 & 0.8421 & 0.7071 \\
\hline $\mathrm{P}$ & 0.5784 & 0.9176 & 0.5965 & 0.8491 & 0.4150 & 0.5784 & 0.9176 & 0.5965 & 0.8491 & 0.4150 \\
\hline Q & 0.5334 & 0.7935 & 0.5389 & 0.6128 & 0.5201 & 0.5334 & 0.7935 & 0.5389 & 0.6128 & 0.5201 \\
\hline $\mathrm{R}$ & 1.0000 & 0.8364 & 0.7495 & 0.7162 & 0.7360 & 1.0389 & 0.8364 & 0.7495 & 0.7162 & 0.7360 \\
\hline S & 0.5382 & 0.7607 & 0.4967 & 0.6902 & 0.3413 & 0.5382 & 0.7607 & 0.4967 & 0.6902 & 0.3413 \\
\hline Average & 0.7042 & 0.7820 & 0.6122 & 0.6815 & 0.5716 & 0.7062 & 0.7876 & 0.6122 & 0.6871 & 0.5771 \\
\hline
\end{tabular}

TABle 5: Efficiency average of all banks from 2016 to 2020.

\begin{tabular}{lccc}
\hline DMU & $\begin{array}{c}\text { The first stage of super-efficiency two- } \\
\text { stage network }\end{array}$ & $\begin{array}{c}\text { The second stage of super-efficiency two- } \\
\text { stage network }\end{array}$ & $\begin{array}{c}\text { Comprehension of super-efficiency two- } \\
\text { stage network }\end{array}$ \\
\hline A & 1.1097 & 1.0541 & 1.0819 \\
B & 0.8755 & 0.7957 & 0.8356 \\
C & 0.7186 & 0.4961 & 0.6074 \\
D & 0.7849 & 0.6338 & 0.7093 \\
E & 0.6922 & 0.8330 & 0.7626 \\
F & 0.5868 & 0.4112 & 0.4990 \\
G & 0.5802 & 0.4928 & 0.5365 \\
H & 0.7038 & 0.8988 & 0.8013 \\
I & 0.5611 & 0.3495 & 0.4553 \\
J & 0.6538 & 0.3861 & 0.5200 \\
K & 0.9032 & 0.4624 & 0.6828 \\
L & 0.7541 & 0.6558 & 0.7050 \\
M & 0.6864 & 0.3137 & 0.5000 \\
N & 0.5448 & 0.2565 & 0.4007 \\
O & 0.7989 & 0.5746 & 0.6867 \\
P & 0.8177 & 0.4163 & 0.6170 \\
Q & 0.7176 & 0.3849 & 0.5512 \\
R & 0.8095 & 0.7770 & 0.7933 \\
S & 0.7070 & 0.3179 & 0.5124 \\
Total & 0.7371 & 0.5532 & 0.6452 \\
average & & &
\end{tabular}

\section{Conclusion}

The two-stage network DEA model solves the problem of "black box" in the DEA model, and super-efficiency is introduced in the two-stage network DEA model to better rank and compare the banks and further distinguish the banks with an efficiency value of 1 . According to the analysis results of each table, the best business efficiency among the selected 19 commercial banks was shown by ICBC and the worst by Ping An Bank, which indicates that the development of the banking industry and the difference between local banks and state-owned banks is large and the state should vigorously develop local banks to make the balanced development of commercial banks in China. In addition, it can also be concluded that the efficiency level of stage 1 and stage 2 can jointly affect the overall efficiency level and the efficiency value of stage 2 is lower for 19 banks during 2016-2020, which indicates that stage 2 has a greater impact on the overall efficiency; thus, the solution measures should be started from the input-output side of stage 2. It is recommended to improve the efficiency of stage 2 by adjusting the asset-liability structure, focusing on credit structure and risk, 
and improving the employee compensation system to increase the overall efficiency from the whole, thus improving the bank's operational efficiency and for earning more profits.

\section{Data Availability}

The data used to support the findings of the study can be obtained from "https://www.eastmoney.com/." Also, banks can be searched directly in the site and the financial analysis of banks can be checked to find the data.

\section{Conflicts of Interest}

The authors declare there are no conflicts of interest regarding the publication of this paper.

\section{Acknowledgments}

This research was funded by the Hunan Philosophy and Social Science Foundation under Project no. 20YBA121.

\section{References}

[1] A. Charnes, W. W. Cooper, and E. Rhodes, "Measuring the efficiency of decision making units," European Journal of Operational Research, vol. 2, pp. 429-444, 1979.

[2] N. Zhu, J. L. Hougaard, Z. Yu, and B. Wang, "Ranking Chinese commercial banks based on their expected impact on structural efficiency," Omega, vol. 94, Article ID 102049, 2020.

[3] K. D. Dimitris, D. Sotiros, and G. Koronakos, "A network DEA approach for series multi-stage processes," Omega, vol. 61, pp. 35-48, 2016.

[4] X. A. Qing, H. X. Chen, J. Wu, and L. Liang, "Measuring slacksbased efficiency for commercial banks in China by using a twostage DEA model with undesirable output," Annals of Operations Reaserch, vol. 235, pp. 13-35, 2015.

[5] O. Jamal and C. Skarleth, "Assessing efficiency profiles of UK commercial banks: a DEA analysis with regression-based feedback," Annals of Operations Reaserch, vol. 266, pp. 551-587, 2019.

[6] J. Wang, X. Jin, X. Wang, and S. L. Wang, "Efficiency evaluation and comparison of Chinese commercial bank based on bootstrap-DEA," Journal of Northeastern University (Natural Science Edition), vol. 39, pp. 1506-1510, 2018.

[7] X. J. Fan, "Efficiency research of Chinese commercial banks based on super-efficiency DEA method," American Journal of Industrial and Business Management, vol. 6, pp. 526-534, 2016.

[8] Y. R. Duan, Y. F. Jing, and G. P. Li, "Efficiency evaluation of Chinese commercial bank based on two-stage DEA method," Operation and Management, vol. 28, pp. 118-125, 2019.

[9] K. Parisa, R. M. Mohammad, G. Javad, and F. W. Peter, "Twostage incentives system for commercial banks based on centralized resource allocation model in DEA-R," International Journal of Productivity and Performance Management, vol. 70, pp. 427-458, 2021. 